\title{
Problems, Stressors and Needs of Children and Adolescents with Cancer
}

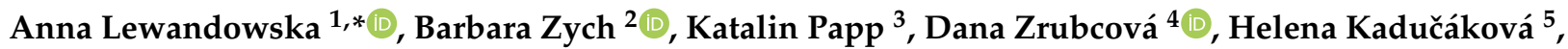 \\ Mária Šupínová ${ }^{5}$, Serap Ejder Apay ${ }^{6}$ and Małgorzata Nagórska ${ }^{7}$ (i)
}

check for

updates

Citation: Lewandowska, A.; Zych, B.; Papp, K.; Zrubcová, D.; Kadučáková, H.; Šupínová, M.; Apay, S.E.;

Nagórska, M. Problems, Stressors and Needs of Children and Adolescents with Cancer. Children 2021, 8, 1173. https://doi.org/10.3390/ children 8121173

Academic Editor: Danielle Novetsky Friedman

Received: 14 October 2021

Accepted: 8 December 2021

Published: 10 December 2021

Publisher's Note: MDPI stays neutral with regard to jurisdictional claims in published maps and institutional affiliations.

Copyright: (C) 2021 by the authors. Licensee MDPI, Basel, Switzerland. This article is an open access article distributed under the terms and conditions of the Creative Commons Attribution (CC BY) license (https:/ / creativecommons.org/licenses/by/ $4.0 /)$.
1 Institute of Healthcare, State School of Technology and Economics, 37-500 Jaroslaw, Poland

Institute of Health Sciences, Medical College of Rzeszow University, 35-310 Rzeszow, Poland; ba.zyc@wp.pl

3 Faculty of Health, University of Debrecen, 4400 Nyíregyháza, Hungary; papp.katalin@foh.unideb.hu

4 Faculty of Social Sciences and Health Care, Constantine the Philosopher University in Nitra, 94974 Nitra, Slovakia; dzrubcova@ukf.sk

5 Faculty of Health, Catholic University in Ružomberok, 03401 Ružomberok, Slovakia; helena.kaducakova@ku.sk (H.K.); maria.supinova@szu.sk (M.Š.)

6 Department of Midwifery, Faculty of Health Science, Ataturk University, Erzurum 25240, Turkey; sejder@atauni.edu.tr

7 Institute of Medical Sciences, Medical College of Rzeszow University, 35-310 Rzeszow, Poland; ma.nagorska@gmail.com

* Correspondence: am.lewandowska@poczta.fm; Tel.: +48-698-757-926

\begin{abstract}
Background: Cancer diseases in children and adolescents are considered to be one of the most serious health problems in the world. It is estimated that about 151,435 cases are diagnosed in children annually. Children with cancer experience many comorbid symptoms related to diagnosis and treatment that can profoundly affect their lives. They experience physical and emotional suffering, which affects their well-being and physical fitness, influencing the prognosis and deteriorating their physical, mental and social functioning. Given the limited data, an attempt was made to assess the problems of the biopsychosocial sphere of need and stressors among children and adolescents treated for cancer. Accurate symptom assessment is essential to ensure high-quality care and effective treatment. Patients and Methods: The qualitative study was conducted in pediatric oncology of hospitals in Poland. Children diagnosed with cancer were invited to participate in the study to assess their problems, stressors and needs. Results: The study included 520 people, where female sex constituted $48 \%$ and male $52 \%$. The mean age of the children is $13.2 \mathrm{SD}=2.5$. Negative experiences related to the disease are experienced by $82 \%$ of children. Among the surveyed children, the most experienced were anxiety (61\%). The conducted research shows that as many as $69 \%$ of all respondents experienced states that indicate severe depression. The most common somatic problems reported by children were pain (58\%). The most dominant areas of life that had a negative impact was body image (85\%). Conclusions: Children and adolescents diagnosed with neoplastic disease experience many problems and stressors in every sphere of life, which undoubtedly affects a high level of unmet needs. The main category of needs concerning the challenges faced by children with cancer was psychological and care problems. In the youth group, the needs were mainly related to education and social support.
\end{abstract}

Keywords: cancer; children; adolescents; problems; stressors; needs

\section{Introduction}

Cancer diseases in children and adolescents are considered to be one of the most serious health problems in the world. It is estimated that about 151,435 cases are diagnosed in children annually [1,2]. According to data from the World Health Organization, approximately 400,000 children and adolescents aged 0-19 are diagnosed with cancer each year. The incidence of cancer in developed countries ranges from 110 to 150 children per million, which means that 1 per 600 to 1 per 450 children will develop cancer during the 
first 15 years of life. In high-income countries where comprehensive services are generally available, more than $80 \%$ of children with cancer are cured. It is estimated that in lowand middle-income countries, $15-45 \%$ are cured [3-5]. In the United States, after accidents, cancer is the second leading cause of death in children aged 1 to 14 . In 2021, around 10,500 children under the age of 15 are expected to be diagnosed with cancer, and around 1190 children under the age of 15 will die from cancer [6]. In the European Region, childhood cancers account for $1-1.5 \%$ of cancers in the total population, with more than 3 million new cases of cancer and 1.7 million deaths each year [1-5]. In Europe, there are approximately 15,000 new cancer cases every year among children from 0 to 14 years of age, and among adolescents and young adults aged 15-24 years, another 20,000 cases. In Poland, 1100-1200 new cases occur per year, and the incidence rate is close to 140-145 new cases per 1 million children and adolescents. In Poland, there are approximately 8 million children and adolescents aged 0 to 17, and approximately 10,000 children received treatment for cancer. In the past decades, the incidence in children has been increasing in both sexes. The average annual rate of incidence increase is about $1.2 \%$ per year [7-12].

Children with cancer experience many comorbid symptoms related to diagnosis and treatment that can profoundly affect their lives. They experience physical and emotional suffering, which affects their well-being and physical fitness, leading to delays or limitation of treatment, influencing the prognosis and deteriorating their physical, mental and social functioning [13-15]. Pediatric oncology shows that stressors related to the disease occur more frequently and more intensely, causing higher anxiety and lower self-esteem. The impact of the diagnosis and experience of cancer in a child may be extreme and permanent, causing crises, also affecting life in adulthood [16-18]. During the disease, new needs emerge, which, if not satisfied, increase the negative effects of neoplastic disease, including the fear of death, depression or reduced pain tolerance [14,19].

Although cancer is a common problem, the knowledge about the experiences of Polish children and adolescents treated for cancer is very limited. Given the limited data, an attempt was made to assess the problems of the biopsychosocial sphere of need and stressors among children and adolescents treated for cancer. Accurate symptom assessment is essential to ensure high-quality care and effective treatment.

\section{Objective of the Research}

The study aims to analyze the problems, stressors and needs of children and adolescents hospitalized due to cancer, which gives the opportunity to better understand the experiences of children, and for health care professionals, it allows a broader view of a child with cancer.

\section{Materials and Methods}

\subsection{Study Design}

The qualitative study was conducted in pediatric oncology and hematology departments of hospitals in Podkarpackie Province in 2009-2019. Hospitals provided treatment and care by the public health care system to pediatric patients diagnosed with cancer. Children diagnosed with cancer were invited to participate in the study to assess their problems, stressors and needs. Due to the small size of the sample, the share of respondents with fairly consistent characteristics was important. The size of the sample resulted from the nature of the study (preliminary study).

Each invited person and their guardian were informed about the purpose of the study. The eligible patient and guardian received an information pack from a research group member. The information package consisted of a letter describing the objectives of the study and its course, a consent form to participate in the study, to be completed if patients are interested in the study, and a no consent sheet if they were not. After informed consent was given by the patient and their caregiver, the patient chose the time and place to participate in a face-to-face interview conducted in the clinic by a research group member. The interview lasted approximately $60 \mathrm{~min}$. In case of the patient's fatigue, the interview 
was divided into parts to maintain their physical and mental comfort. All participants were asked the same questions, and the interviewer was able to explain the content of the questions if necessary. However, the questions did not seem difficult for any participant, including younger ones, and no explanations were needed.

\subsection{Participant Recruitment, Inclusion and Exclusion Criteria}

The inclusion criteria were the confirmed diagnosis of childhood cancer in the pathological report, age from 10 to 18 years, no previous chronic or life-threatening disease, knowledge of the Polish language and the consent and willingness of parents to participate in the study. Eligible participants were randomly selected from the general population. The main indicators of participation in the study were the cancer diagnosis at least three months before the study, life expectancy $>6$ months, age and awareness of the diagnosis.

The exclusion criterion was the diagnosis of neoplastic disease shorter than three months because the initial period of diagnosis and treatment is associated with an enormous psychological burden and the need to adapt to the patient's situation, which may introduce errors in the results. The study excluded patients with cognitive impairment, patients who did not express their willingness to participate in the study, those under that could not speak Polish.

\subsection{Participants}

Children and adolescents were invited to participate in the study during their hospitalization. Each invited person was informed about the purpose of the study. After obtaining the written, informed consent of the child and the guardian, the subject was interviewed. The participants chose the place and time of the conversation and decided whether they wanted the parent's participation in the conversation. The non-participation rate was $10 \%$. Parents of children who chose not to participate reported that they did not have enough time or that their children were tired or not feeling well. Non-participation data are not available.

\subsection{Research Procedures}

The study was approved by the Bioethics Committee (Resolution No. 386/2009 and 4 December 2017). Participation in this study was voluntary and anonymous, and respondents were informed of their right to refuse or withdraw from the study at any time. Each participant was informed about the purpose of the study and the time of completion of the study. Families were invited to participate during the child's hospitalization or an outpatient visit. After giving informed consent, the parents completed the questionnaire.

\subsection{Method}

\subsubsection{Clinical Interview}

The method used in the research was a clinical, direct, individual, structured interview, which was in-depth and focused. The qualitative interview was a standardized measuring instrument, verified by testing a group of 20 patients during the month. It contained open-ended, single and multiple-choice questions, allowing to obtain demographic and epidemiological information concerning problems related to the disease: daily stressors of the child, somatic, psychological and social problems and needs.

\subsubsection{Visual Analogue Scale (VAS)}

It is a reliable tool for determining the severity of pain. Cyclically repeated measurements of pain intensity using the VAS scale enable the assessment of the effectiveness of analgesic treatment. The scale is a $10 \mathrm{~cm}$ ruler, where 0 is no pain at all, 1-3 is mild, 4-6 is moderate and $7-10$ is severe.

\subsubsection{Beck Questionnaire for Children to Assess Emotional and Social Disorders (BYI)}

This questionnaire is used as an aid in individual diagnostics, serving to objectify and quantify the degree of disturbances in the child's functioning. It is a tool covering a wide 
spectrum of disorders, intended for filling by schoolchildren. It can be used in situations where it is not possible to obtain information from parents or serve as a supplement to them, constituting an important source of information on the child's functioning. Having a high score for your child can help highlight symptoms that would otherwise go unnoticed and allow them to be referred to a specialist. The scale consists of 21 multiple-choice questions, in which one should give one of four possible answers, and then summarize the obtained points and compare them to the norms: no depression (0-11 points), mild depression (12-19 points), moderate depression (20-25 points) and severe depression ( $26-63$ points).

\subsection{Data Analysis}

The analysis used descriptive statistics and confidence intervals in the assessment of participants' characteristics, metric and demographic data, and in the assessment of problems. Statistical characteristics of continuous variables are presented in the form of arithmetic means, standard deviations and medians. Statistical characteristics of step and qualitative variables were presented in the form of numerical and percentage distributions, using the Student $t$-test or the Mann-Whitney $\mathrm{U}$ test. Correlations were determined using Pearson's test, while $\chi^{2}$ was used for intergroup comparison. Significance was assessed at the level of $p<0.05$. The manuscript presents the results regarding the comparison of arithmetic means and standard deviation obtained on the Beck scale. The non-parametric t-Student test was used for the comparative analysis. Following the applicable statistical principles, raw results were used for intergroup comparisons. The repeatability of answers to individual questions was assessed using Kappa Cohen statistics.

\section{Results}

\subsection{Demographic Data}

The study included 520 people, where female sex constituted $48 \%$ and male $52 \%$. The mean age of the children is $13.2 \mathrm{SD}=2.5$. Hospitalized for the first time constituted $52 \%$ of all respondents, once again $48 \%$. The data analysis shows that the most common neoplasms in the study group are leukemias (44\%). All children had a caregiver; most were mothers $(83 \%)$, while the remaining $17 \%$ were fathers. All participants received chemotherapy $(100 \%)$. In total, $25 \%$ of the respondents were primary school students, $41 \%$ were middle school students and $34 \%$ were high school students. Other descriptive statistics identifying the studied group are presented in Table 1.

Table 1. Descriptive statistics of the examined group of patients.

\begin{tabular}{ccc}
\hline Demographic Information & $\begin{array}{c}\text { Total } \\
n=520\end{array}$ & $p$ \\
\hline & Characteristics $\%(n)$ & \multirow{2}{*}{0.19} \\
\hline girls & $48 \%(250)$ & \\
\hline boys & $52 \%(270)$ \\
\hline SD & The age of the study group \\
\hline $95 \% C I$ & $13.2(2.51)$ \\
\hline city & $<10 ; 18>$ \\
\hline village & Place of residence \\
\hline
\end{tabular}


Table 1. Cont.

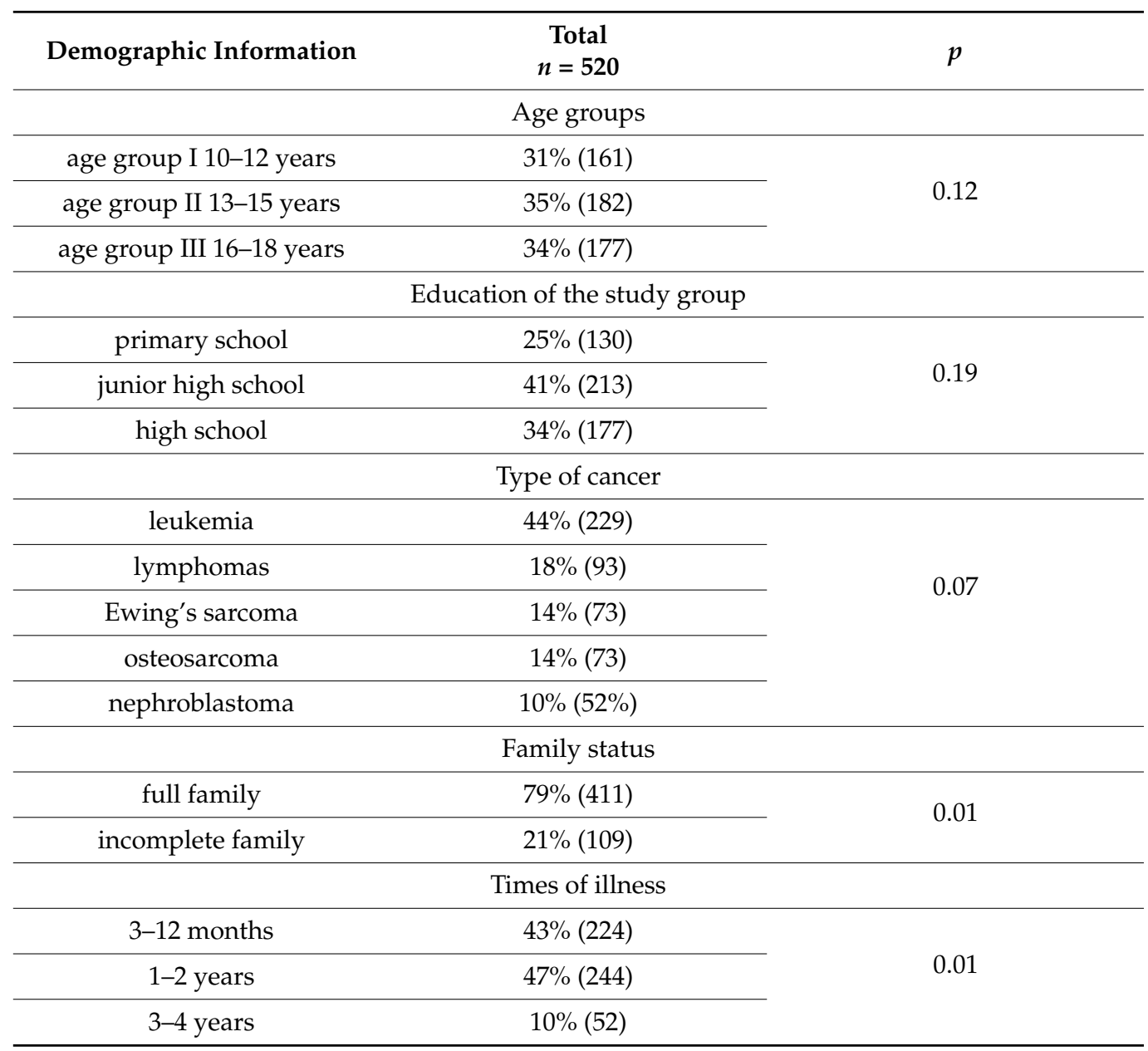

\subsection{Psychological Problems}

Negative experiences related to the disease are experienced by $82 \%$ (95\% CI: 79-85) of children. Among the surveyed children, the most experienced were anxiety $(61 \%, 95 \% \mathrm{CI}$ : 60-63), depression (58\%, 95\% CI: 55-60) and anger (33\%, 95\% CI: 31-35) (Figure 1). As many as $42 \%$ (95\% CI: 39-45) of children could not come to terms with the disease, $28 \%$ (95\% CI: 27-30) with hospitalization, 20\% (95\% CI: 19-22) with homesickness, $16 \%$ (95\% CI: 14-18) with parents' emotions and suffering, $14 \%$ (95\% CI: 10-18) with unjust fate and 24\% (95\% CI: 19-28) with a lack of physical activity. The factors negatively influencing well-being mentioned by patients were most often isolation (76\%, 95\% CI: 75-78) (Figure 2). Subsequently, the intensification of features indicating the existence of depression in children was examined. Comparison of the results obtained on the Beck scale in groups of girls and boys shows statistically significant differences $(p<0.01)$. Girls experienced emotional states indicative of depression relatively more often than boys. It was necessary to convert the raw results obtained on the Beck scale according to the norms to determine the number of people affected by the problem of depression. The conducted research shows that as many as $69 \%$ of all respondents (95\% CI: 63-72) experienced states that indicate severe depression (Table 2). Then, the differences in the children's depression in terms of hospitalization time were determined. A comparison of the arithmetic means and standard deviation obtained on the Beck Depression Scale showed no significant differences $(p<0.94)$. This means that the severity of depression features among children with the comparison of hospitalization time is similar (Table 3). 


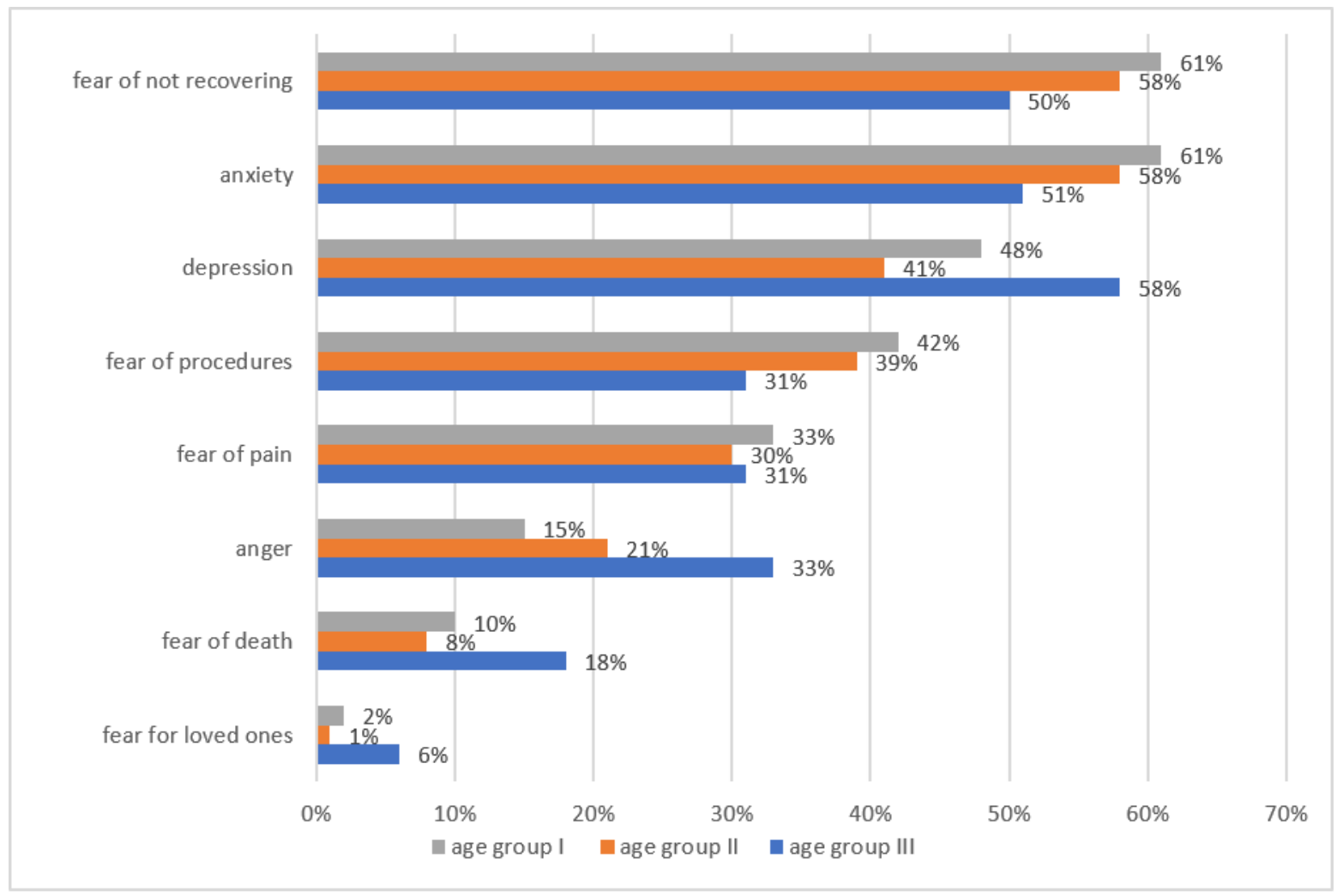

Figure 1. Negative experiences related to the disease among the respondents.

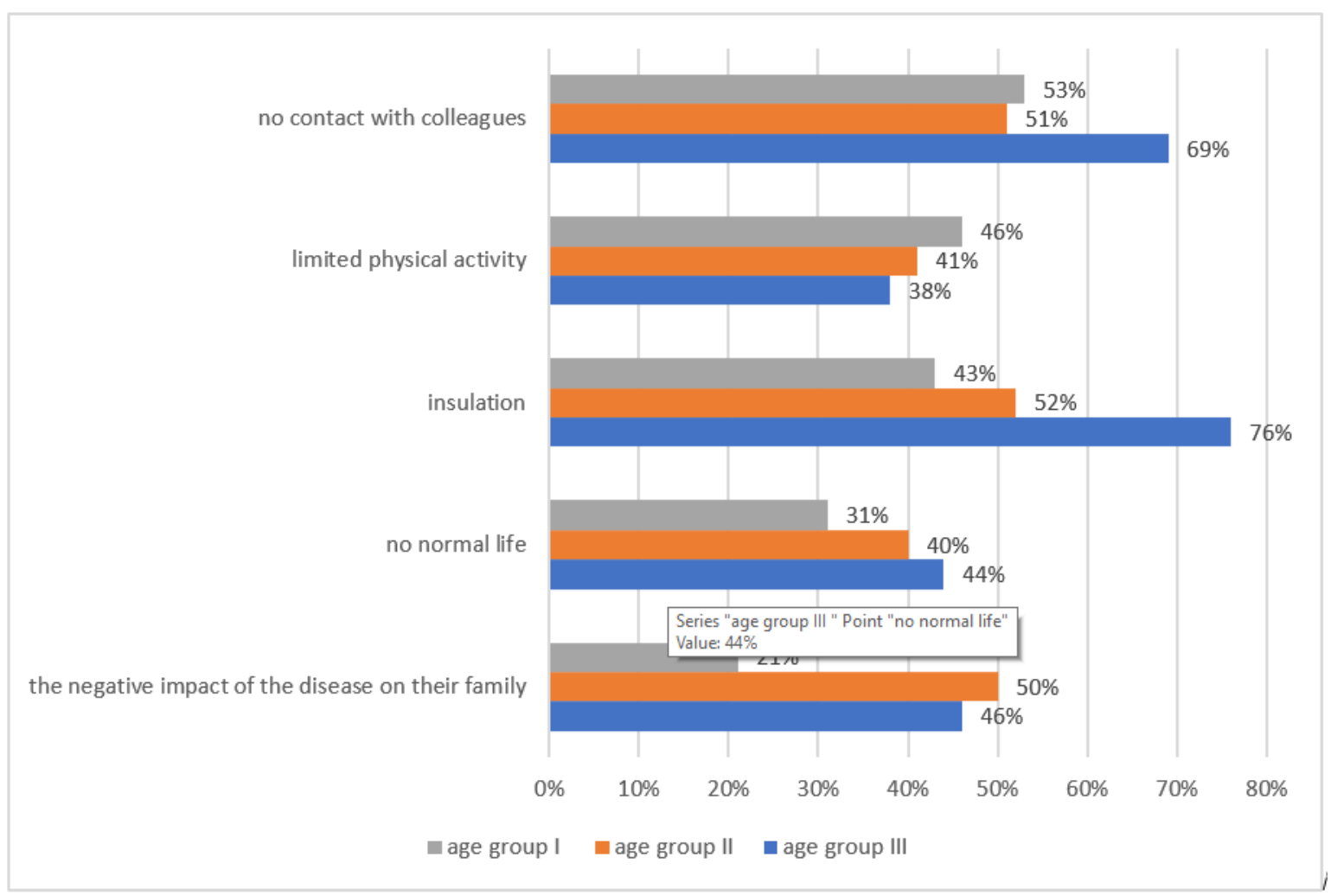

Figure 2. Factors negatively influencing the well-being of the respondents. 
Table 2. Severity of depression on the Beck scale.

\begin{tabular}{cccccccc}
\hline \multirow{2}{*}{ Factors } & \multicolumn{3}{c}{ Girls } & \multicolumn{2}{c}{ Boys } & \multirow{2}{*}{$\mathbf{t}$} & \multirow{2}{*}{$\boldsymbol{p}$} \\
\cline { 2 - 6 } & $\mathbf{x}^{-}$ & $\mathbf{s}$ & $\mathbf{x}^{-}$ & $\mathbf{s}$ & & \\
\hline Beck scores & 32.2 & 9.4 & 27.7 & 8.6 & & 4.2 & 0.01 \\
\hline
\end{tabular}

Table 3. Severity of depression on the Beck scale.

\begin{tabular}{|c|c|c|c|c|c|c|}
\hline \multirow{2}{*}{ Factors } & \multicolumn{2}{|c|}{ First Hospitalization } & \multicolumn{2}{|c|}{$\begin{array}{c}\text { Second } \\
\text { Hospitalization }\end{array}$} & \multirow[t]{2}{*}{$\mathbf{t}$} & \multirow[t]{2}{*}{$p$} \\
\hline & $x^{-}$ & s & $x^{-}$ & s & & \\
\hline Beck scores & 29.9 & 10.1 & 30.2 & 11.1 & 0.20 & 0.94 \\
\hline
\end{tabular}

\subsection{Communication Problems}

All examined children were aware of the disease $(100 \%)$. The vast majority of them received information about the disease from their parents (69\%, 95\% CI: 67-71), while the remaining children received such information from health care professionals $(31 \%, 95 \% \mathrm{CI}$ : 30-32). When assessing the impact of the disease on the child's contacts with family and friends, it was shown that children most often complained of communication problems due to isolation (79\%, 95\% CI: 77-81), shame about appearance (67\%, 95\% CI: 65-70) and overprotection (35\%, 95\% CI: 33-37). Most parents spent a great deal of time with their children visiting them daily (82\%, 95\% CI: 80-84); however, 88\% (95\% CI: 87-89) of children would like to spend more time with their family. According to $64 \%$ (95\% CI: 62-66) of the respondents, parents had not changed their attitude towards them since the diagnosis of the disease, $28 \%$ (95\% CI: 27-29) believed that they had become more caring and 8\% (95\% CI: 7-9) that they had more time for them. The changes in parents' behavior noticed by the children were mainly sadness (54\%, 95\% CI: 52-58) (Figure 3). A total of 76\% (95\% CI: 74-79) of patients maintained contact with their peers less than once a week, while only $6 \%$ (95\% CI: 5-8) were visited by their peers every day. Only 20\% (95\% CI: 17-23) attended hospital school, $62 \%$ (95\% CI: 60-65) were educated with parental support and 18\% (95\% CI: 15-20) were not educated. 


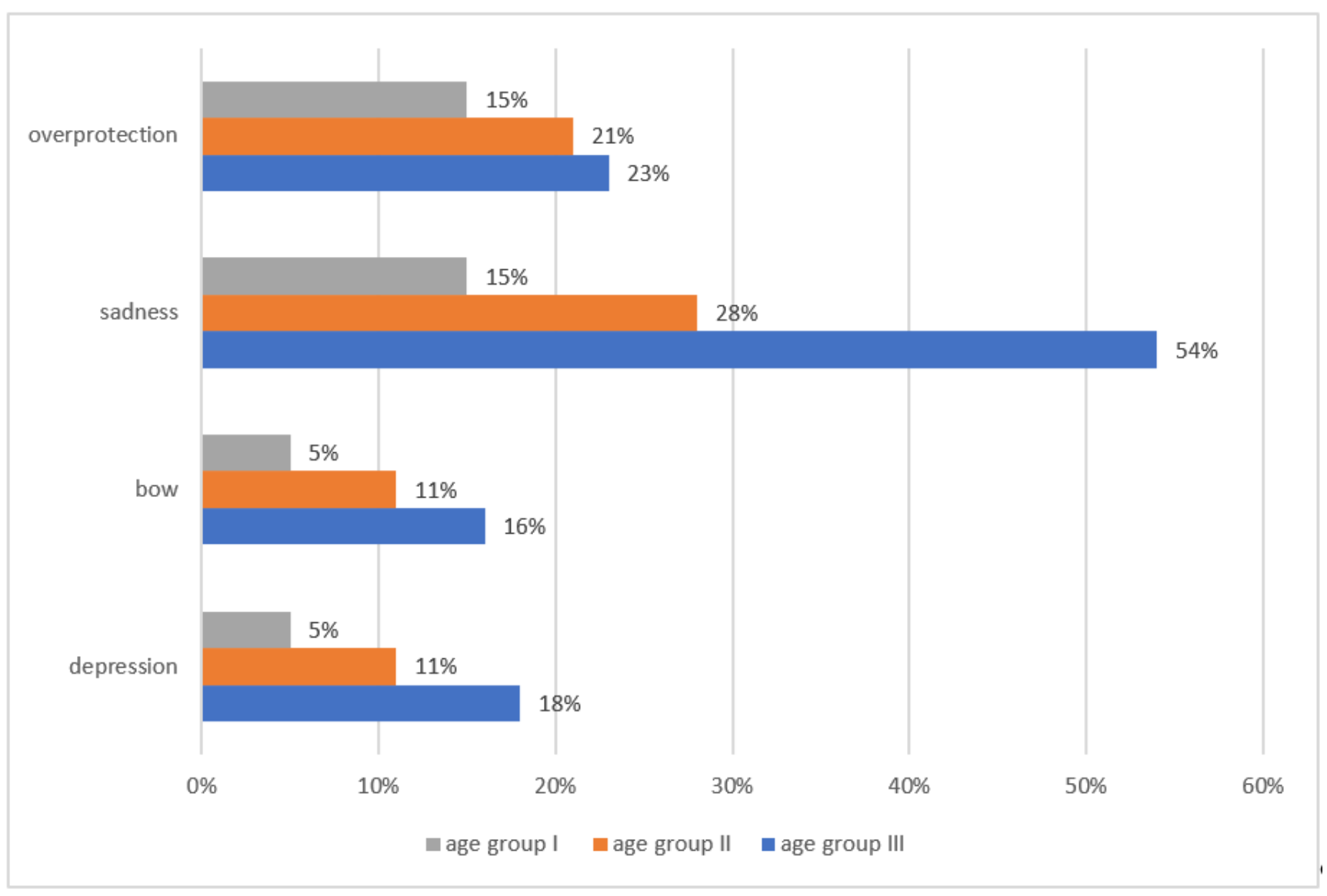

Figure 3. Changes in parents' behavior noticed by the respondents.

\subsection{Somatic Problems}

The most common somatic problems reported by children were pain ( $58 \%$, 95\% CI: 55-60), weakness (51\%, 95\% CI: 48-55) and vomiting (39\%, 95\% CI: 35-42) (Table 4). In assessing pain intensity on the VAS scale, the mean was $57 \%$ (95\% CI: $54-59)$. The proportion of patients assessing their mean pain in the last week as mild was 22\% (95\% CI: 19-25), moderate $48 \%$ (95\% CI: 45-49) and severe 30\% (95\% CI: 28-32). The children most frequently indicated that pain peaked in the morning and decreased over the day $(88 \%$, 95\% CI: 85-91). Younger children experienced breakthrough pain more often than adolescents ( $73 \%$ vs. $33 \%, p \leq 0.01)$. Gender was not significantly correlated, as was the incidence of breakthrough pain with anxiety or depression. Children usually described the pain as acute (79\%, 95\% CI: 75-81).

Table 4. Somatic symptoms among respondents.

\begin{tabular}{|c|c|c|c|c|c|c|c|}
\hline \multirow{2}{*}{ Symptoms } & \multicolumn{3}{|c|}{ Age } & \multirow{2}{*}{$p$} & \multicolumn{2}{|c|}{ Sex } & \multirow{2}{*}{$p$} \\
\hline & $10-12$ & 13-15 & $16-18$ & & Girls & Boys & \\
\hline \multicolumn{8}{|c|}{ Characteristics $n / \%$} \\
\hline Pain & $60 \%(97)$ & $55 \%(100)$ & $21 \%(37)$ & 0.01 & $60 \%(150)$ & $55 \%(148)$ & 0.91 \\
\hline Nausea & $13 \%(21)$ & $10 \%(18)$ & $10 \%(18)$ & 0.41 & $13 \%(32)$ & $10 \%(27)$ & 0.55 \\
\hline Vomiting & $56 \%(90)$ & $39 \%(71)$ & $19 \%(34)$ & 0.01 & $56 \%(140)$ & $42 \%(113)$ & 0.44 \\
\hline Weakness & $56 \%(90)$ & $46 \%(84)$ & $27 \%(48)$ & 0.77 & $56 \%(140)$ & $42 \%(113)$ & 0.55 \\
\hline Somnolence & $28 \%(45)$ & $27 \%(49)$ & $11 \%(19)$ & 0.91 & $30 \%(75)$ & $27 \%(73)$ & 0.91 \\
\hline
\end{tabular}


Table 4. Cont.

\begin{tabular}{|c|c|c|c|c|c|c|c|}
\hline \multirow{2}{*}{ Symptoms } & \multicolumn{3}{|c|}{ Age } & \multirow{2}{*}{$p$} & \multicolumn{2}{|c|}{ Sex } & \multirow{2}{*}{$p$} \\
\hline & $10-12$ & $13-15$ & $16-18$ & & Girls & Boys & \\
\hline Fatigue & $48 \%(77)$ & $37 \%(67)$ & $31 \%(55)$ & 0.54 & $48 \%(120)$ & $37 \%(100)$ & 0.91 \\
\hline Difficulty sleeping & $23 \%(37)$ & $30 \%(55)$ & $30 \%(53)$ & 0.55 & $23 \%(57)$ & $30 \%(81)$ & 0.71 \\
\hline Difficulty concentrating & $16 \%(26)$ & $30 \%(55)$ & $44 \%(78)$ & 0.01 & $46 \%(115)$ & $30 \%(81)$ & 0.74 \\
\hline $\begin{array}{l}\text { Loss of the ability to do } \\
\text { things before getting sick }\end{array}$ & $38 \%(61)$ & $17 \%(31)$ & $31 \%(55)$ & 0.41 & $40 \%(100)$ & $37 \%(100)$ & 0.91 \\
\hline $\begin{array}{l}\text { Inflammation of the oral } \\
\text { mucosa }\end{array}$ & $13 \%(21)$ & $10 \%(18)$ & $19 \%(34)$ & 0.81 & $23 \%(57)$ & $18 \%(49)$ & 0.55 \\
\hline
\end{tabular}

\subsection{Caring Problems}

Factors that, in the opinion of children and adolescents, adversely affected their stay in the ward included limitations in going outside (68\%, 95\% CI: 67-69), multiple procedures (40\%, 95\% CI: $39-41)$, no intimacy ( $36 \%, 95 \%$ CI: $34-39)$ as well as unfriendly staff $(6 \%, 95 \%$ CI: 4-9). Despite the presence of factors hindering hospitalization, patients were also able to perceive amenities. The most popular entertainment preferred by respondents is watching TV (56\%, 95\% CI: 54-59) and computer games (48\%, 95\% CI: 45-49) (Figure 4). The study also attempted to assess the impact of hospital staff on the hospitalization process. Nursing staff assessed 46\% (95\% CI: 45-49) children very well, medical staff rated 14\% (95\% CI: $12-18)$ patients very well, while $40 \%$ (95\% CI: 38-44) negatively assessed the staff. In total, $80 \%$ (95\% CI: 79-81) of patients did not confide in health professionals and only $20 \%$ (95\% CI: 18-22) talked to workers about illness and anxiety.

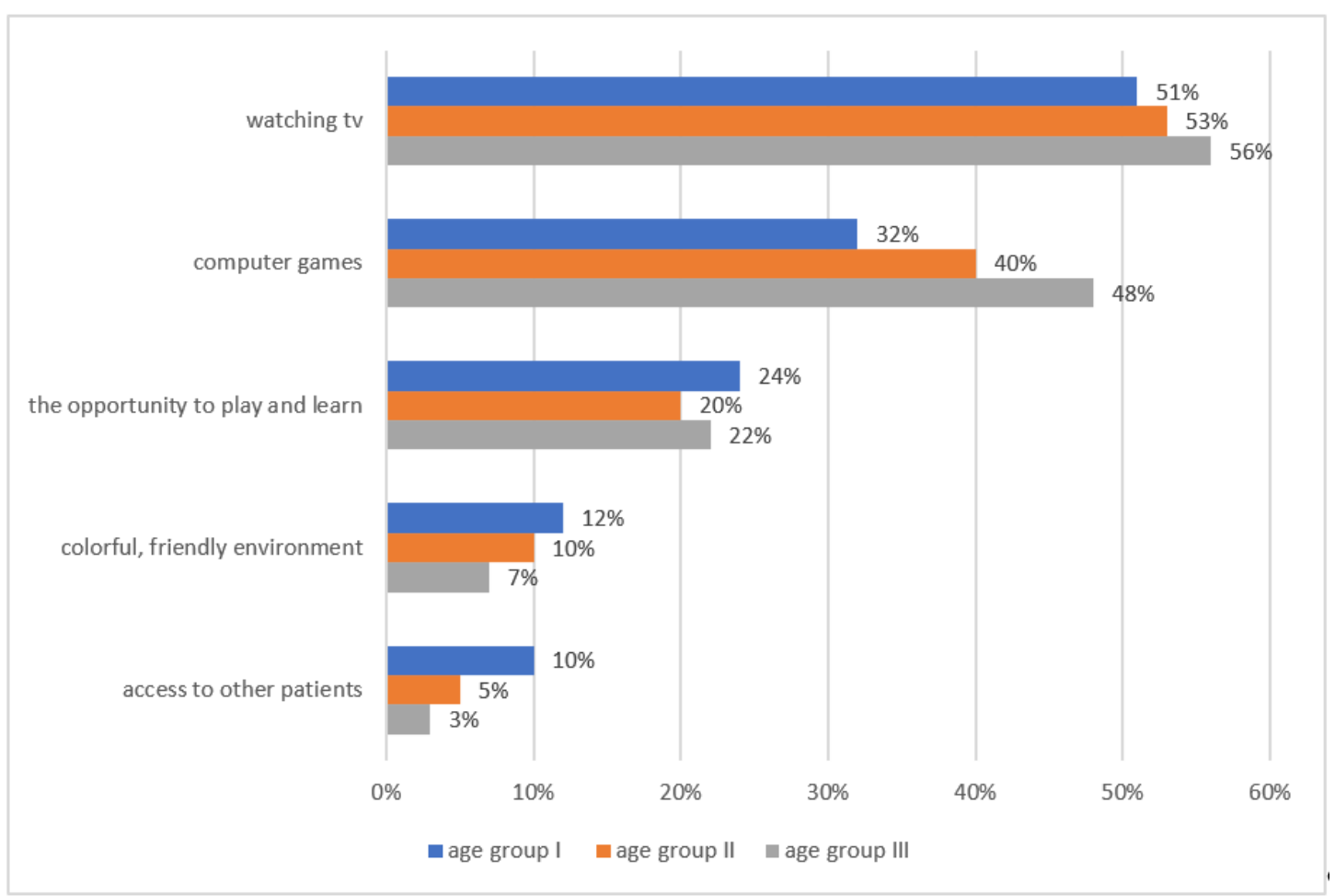

Figure 4. Hospital facilities appreciated by respondents. 


\subsection{Stressors}

In the study, children and adolescents were asked about the stressors that are of the greatest importance to them. With little differences between the age groups, the most dominant areas of life that had a negative impact were body image (85\%, 95\% CI: 84-86), life control (57\%, 95\% CI: 55-58) and plans for the future (27\%, 95\% CI: 24-29). Significant differences in the negative impact items for the younger age group compared to the older age group concerned education plans $(17 \%$ : vs. $38 \% p<0.01)$ and peer relationships $(44 \%$ vs. $58 \% ; p<0.01)$. Young people were significantly more worried about their parents' finances $(p=0.01)$ (Table 5).

Table 5. Stressors among the respondents.

\begin{tabular}{|c|c|c|c|c|c|c|c|}
\hline \multirow{2}{*}{ Stressors } & \multicolumn{3}{|c|}{ Age } & \multirow{2}{*}{$p$} & \multicolumn{2}{|c|}{ Sex } & \multirow{2}{*}{$p$} \\
\hline & $10-12$ & 13-15 & $16-18$ & & Girls & Boys & \\
\hline \multicolumn{8}{|c|}{ Characteristics $n / \%$} \\
\hline parents' finance & $10 \%(16)$ & $7 \%(13)$ & $21 \%(37)$ & 0.91 & $22 \%(55)$ & $17 \%(46)$ & 0.91 \\
\hline body image change & $83 \%(134)$ & $80 \%(146)$ & $86 \%(152)$ & 0.41 & $93 \%(232)$ & $86 \%(232)$ & 0.12 \\
\hline lack of control over life & $26 \%(42)$ & $55 \%(100)$ & $58 \%(103)$ & 0.81 & $56 \%(140)$ & $58 \%(157)$ & 0.44 \\
\hline educational plans & $17 \%(27)$ & $26 \%(47)$ & $38 \%(67)$ & 0.01 & $40 \%(100)$ & $36 \%(97)$ & 0.55 \\
\hline plans for the future & $18 \%(29)$ & $27 \%(49)$ & $29 \%(51)$ & 0.01 & $30 \%(75)$ & $27 \%(73)$ & 0.19 \\
\hline family relationships & $18 \%(29)$ & $7 \%(13)$ & $11 \%(20)$ & 0.41 & $18 \%(45)$ & $7 \%(19)$ & 0.91 \\
\hline relationships with peers & $44 \%(71)$ & $40 \%(73)$ & $58 \%(103)$ & 0.01 & $43 \%(107)$ & $40 \%(108)$ & 0.55 \\
\hline
\end{tabular}

\subsection{Needs}

The most common unmet needs were psychological needs, care needs and social needs (Table 6). Age was associated with a higher level of unmet needs in the fields of psychology, health care and support. Children consistently showed a higher level of unmet needs than adolescents $(p=0.01)$.

Table 6. Patients' needs.

\begin{tabular}{|c|c|c|c|c|}
\hline \multirow[t]{2}{*}{ Needs } & \multicolumn{3}{|c|}{$\underset{\%}{\text { High Needs/Moderate Needs }}$} & \multirow[t]{2}{*}{$95 \% \mathrm{Cl}(\%)$} \\
\hline & $10-12$ & 13-15 & $16-18$ & \\
\hline \multicolumn{5}{|c|}{ Social needs } \\
\hline emotional support from society & 93 & 55 & 59 & $54-95$ \\
\hline support through prayer & 90 & 73 & 70 & $69-93$ \\
\hline financial assistance & 85 & 64 & 55 & $50-91$ \\
\hline material support & 40 & 35 & 29 & $25-41$ \\
\hline the need for contacts with peers & 45 & 30 & 38 & $36-48$ \\
\hline \multicolumn{5}{|c|}{ Caring needs } \\
\hline improvement of conditions in the hospital & 31 & 30 & 29 & $21-30$ \\
\hline home treatment support & 39 & 32 & 23 & $20-41$ \\
\hline better quality of care & 24 & 28 & 44 & $20-46$ \\
\hline supports from nurses and doctors & 40 & 36 & 25 & $22-40$ \\
\hline $\begin{array}{l}\text { financial support for treatment and } \\
\text { rehabilitation }\end{array}$ & 19 & 21 & 30 & $18-33$ \\
\hline \multicolumn{5}{|c|}{ Educational need } \\
\hline better cancer education & 25 & 31 & 39 & $20-42$ \\
\hline access to hospital education & 57 & 59 & 67 & $51-72$ \\
\hline support in further education & 44 & 41 & 66 & $41-72$ \\
\hline
\end{tabular}


Table 6. Cont.

\begin{tabular}{|c|c|c|c|c|}
\hline \multirow[t]{2}{*}{ Needs } & \multicolumn{3}{|c|}{$\begin{array}{c}\text { High Needs/Moderate Needs } \\
\%\end{array}$} & \multirow[t]{2}{*}{$95 \% \mathrm{Cl}(\%)$} \\
\hline & $10-12$ & 13-15 & $16-18$ & \\
\hline \multicolumn{5}{|c|}{ Psychological needs } \\
\hline need for love & 73 & 54 & 43 & $42-77$ \\
\hline $\begin{array}{l}\text { the need for compassion on the part of nurses, } \\
\text { doctors }\end{array}$ & 88 & 47 & 28 & $25-90$ \\
\hline the need for contact with loved ones & 93 & 80 & 72 & $69-97$ \\
\hline \multicolumn{5}{|c|}{ Physical needs } \\
\hline help with everyday activities & 85 & 31 & 25 & $20-87$ \\
\hline
\end{tabular}

\section{Discussion}

Our study is one of the few that identifies problems and needs among children treated for cancer in Poland. This study focused on somatic, emotional and social problems and needs resulting from illness and hospitalization.

The first thread of this study showed that children had numerous psychological problems resulting from the disease. In total, $82 \%$ of children have negative experiences related to the disease; most often, this was fear $(61 \%)$, depression $(58 \%)$ and anger $(33 \%)$. The factor negatively influencing wellbeing mentioned by patients was most often isolation $(76 \%)$. Similar results were obtained by Reisi-Dehkordi et al., demonstrating that children had psychological problems in contact with the disease; it was found that depression, anxiety and aggression were common among children with cancer [20]. Additionally, the study by Kohi et.al showed that the children were emotionally affected, felt separated from family members and had negative feelings related to the diagnosis [21], which was also confirmed by other studies [22,23]. The results presented by Dyson et al. also showed that only a few participants $(17 \%)$ presented a lower level of distress and unmet psychological needs [24]. Similarly to our studies, where $69 \%$ of the respondents experienced conditions indicative of severe depression in the past, studies by Hedström and others showed that $12 \%$ of children reached the cut-off point for potential clinical anxiety and $21 \%$ for potential clinical depression. Mental health and vitality scores were lower than the normative values [25]. The problem of depression is generally more common in girls than boys, which our research also confirms. Girls experienced emotional states indicative of depression relatively more often than boys $(p<0.01)$. This is true of both so-called severe and moderate depression. According to the classification of mental and behavioral disorders, severe depression is linked to feelings of worthlessness, low self-esteem, guilt and suicidal thoughts. Moderate depression is characterized by the loss of interest and pleasure, as well as increased fatigue [26]. What is very worrying among people who obtained a result in the clinical scope of depression, a higher frequency of pain associated with procedures, treatment [25], sleep, appetite, concentration disorders and fatigue were more frequent $[25,26]$. The results of a study by Verberne et al. showed that children with cancer developed insomnia, causing fatigue and deterioration of their functions [27].

Another element of this study showed that children had communication problems in contact with the disease. What hinders communication are isolation (79\%) and shame about appearance $(67 \%)$, as well as changes in parents' behavior noticed by children. The vast majority of patients maintained contact with their peers less than once a week. Our results are in line with the research of Lee et al., where patients encountered interpersonal communication problems due to a disease affecting their body image [28]. Kamper et al. claimed that peers paid special attention to the patient due to their illness, which hindered their interpersonal communication [29]; in the study by Reisi-Dehkordi et al., peers isolated patients due to the disease [20].

Somatic problems, which are complex and change over time, are a major challenge in pediatric oncology. Pain and treatment side effects, especially nausea, are a constant problem for many children and adolescents with cancer, as confirmed by numerous studies [22,30-35]. 
Regardless of whether the pain is associated with the disease, treatment or procedures, it is the most frequently identified and effectively treated symptom in children and adolescents [36]. Van Cleve et al. showed that the highest mean pain intensity scores in children with acute lymphoblastic leukemia were directly related to disease development and treatment or diagnostic procedures. The children indicated that the most common places of pain were legs, abdomen, head, neck and back [37]. In our research, assessing pain intensity on the VAS scale, the mean was $57 \%$. The proportion of patients assessing their mean pain in the last week as mild was $22 \%$, moderate $48 \%$ and severe $30 \%$. The children most frequently indicated that pain peaked in the morning and decreased over the day $(88 \%)$. Fatigue and excessive sleepiness seem to be equally significant problems for cancer patients [32,33,38-41], as well as the loss of the ability to do things as before (e.g., playing sports, playing and studying) [22,39]. The study of potential factors contributing to fatigue, such as sleep disturbances, was made a priority in childhood cancer research. The main aim of the study by Zupanec et al. was to investigate the relationship between sleep habits, sleep disturbances and fatigue in children receiving maintenance chemotherapy. Sleep disturbances were common in children (87\%) and the results of sleep disturbances were positively correlated with the assessment of fatigue [38]. A study by Hedström et al. showed that in children 12 years of age or younger, the most frequently mentioned and most disturbing symptoms were pain associated with diagnostic procedures and treatment, nausea and fatigue while in children 13 years of age or older, the most bothersome symptom was nausea. In adolescents, physical symptoms and emotional stress were related [42]. In another study, it was shown that for most adolescents, the greatest concerns were related to the deterioration of health, mucositis, nausea, pain caused by procedures and treatments and leaving school [43]. In the publication by Enskär and von Essen, it was found that two-thirds of the children tested experienced physical symptoms. Children treated for cancer significantly more often reported worries about hair loss (47\% vs. $10 \%)$ and nausea (47\% vs. $14 \%)(p<0.05$ for each) and fatigue (65\% vs. $43 \%$ ) compared to children who ended treatment [44]. Other authors found that physical suffering, defined as fatigue, eating problems, hair loss and problems taking medications, was reported by two-thirds of adolescents undergoing cancer treatment. More than half of the adolescents who completed treatment reported that fatigue and eating problems continued, and that life was less fulfilling $[45,46]$. The above considerations confirm our results, where the most frequently reported symptoms by children were pain (58\%), weakness (51\%) and vomiting (39\%).

Another piece of the study showed that children who were exposed to the disease faced care problems. Factors that, in the opinion of children, adversely affected their stay in the ward were mainly limitations in going outside (68\%) and the multiplicity of procedures $(40 \%)$. Despite the presence of factors hindering hospitalization, patients were also able to perceive amenities. The most popular entertainment preferred by respondents is watching TV $(56 \%)$ and computer games (48\%). In studies by Chien et al., participants expressed concerns about poor oncology care associated with misdiagnosis, as well as treatment leading to multiple visits to healthcare before a correct diagnosis [22]. Similar problems were presented in the Edwards and Greeff studies, which identified challenges with poor services, including the need to travel long distances for treatment, poor care in hospitals and delays in cancer diagnosis [47]. No other studies were found for the subcategory of care problems in children and adolescents.

Studies involving children and adolescents with cancer who are cancer survivors clearly show that cancer and its treatment can affect various spheres of life [48]. However, little is known about the stressors that children feel are of the greatest importance to them. One of the first studies in this area was carried out by McCaffrey, in which children spoke about cancer-related stressors in individual interviews. The main stressors were medication and procedures, loss of body image control, fear of death, alopecia and the inability to be with friends. Experiencing these stressors resulted in low self-esteem, feelings of unhappiness or fatigue, becoming more mature than their friends, dropping out of school and not participating in sports and weight loss [49]. In another study, one of the more frequently reported stressors was poor body image, which may lead to low self- 
esteem and affect the ability to form healthy peer relationships [50]. In the study of body image and social adaptation in adolescents with cancer and healthy controls by Pendley et al., body image was assessed more negatively in cancer patients, and this negative assessment was more pronounced for a longer time after treatment [51]. In the studies by Bellizzi et al., the most frequently reported negative life domains in adolescents with cancer were the financial situation, body appearance, sense of control over life and disruption of education [52]. The pediatric literature suggests that time spent outside of school as a result of treatment may have severe effects, such as depression, poor self-esteem and lack of interest, as well as longer-term effects, such as loss of purpose or difficulty re-engaging in educational activities [53]. As a result of limited access to other studies, especially in recent years, we have attempted to identify stressors for adolescents. The stressors that matter most to them are the negative impact of the disease on their body image (85\%), a negative impact on their plans for the future $(27 \%)$, and the lack of control over their lives $(57 \%)$. Our results confirm previous reports, and what is most interesting, we showed significant differences among age groups.

In the last part of the study, the presence of needs among the surveyed children was assessed. This is a particularly important issue as the unmet psychosocial needs of children and adolescents with cancer increase the negative effects of cancer, fear of death, depression, reduced pain tolerance and disability [18]. This may lead to unnecessary, repeated, frequent hospitalizations or invasive procedures and lowered quality of life [54]. According to our results, children and adolescents most often reported psychological needs, care needs, as well as physical and life needs. Kohi et al. identified needs which included the need for improved hospital care by staff, the need for community support, financial needs, the need for better cancer care and treatment in hospitals and the need for increased cancer education [21]. Research by Bonevski and others shows that the most common needs are to provide more information about the diagnosis and prognosis $(63 \%)$, to improve communication with doctors $(50 \%)$, increase intimacy in doctor's offices $(85 \%)$ and improve the organization of care (76\%) [55]. On the other hand, Dyson et al. showed that the most often unmet needs were physical and life needs, followed by psychological needs, needs related to the healthcare system and information and needs related to care and support [24]. What our research has shown is that age was associated with a higher level of unmet needs in the fields of psychology, health care and support.

Our qualitative study includes many predictors of cancer in children and adolescents. The problems, stressors or needs of cancer treatment usually do not occur in isolation, but often occur as multiple problems simultaneously. Our research is multiplicative, which probably supplements the existing gaps in the literature. Most of the research on children remains descriptive. Intervention studies that focus on the problems identified are lacking. In addition, the strength of the study is the confirmation of the results of the studies described in the literature, and the obtained results provide better insight into the analysis of the problems of children and adolescents in all areas of life.

The limiting factors are the small size of the research sample and its heterogeneity in terms of diagnosis. Access to the sample is difficult, so we are planning multi-center studies in the future to help develop larger datasets on age groups. We are in the process of reporting studies from all over Poland to other countries.

\section{Conclusions}

1. Children and adolescents diagnosed with neoplastic disease experience many problems and stressors in every sphere of life, which undoubtedly affects the high level of unmet needs. The main category of needs concerning the challenges faced by children with cancer was psychological and care problems. In the youth group, the needs were mainly related to education and social support.

2. A thorough symptom assessment at an early stage and during treatment is essential in caring for the development of early and supportive interventions for children and adolescents with cancer. 
Author Contributions: Conceptualization, A.L. and S.E.A.; methodology, A.L.; software, A.L. and M.N.; validation, A.L., B.Z. and H.K.; formal analysis, A.L.; investigation, A.L.; resources, A.L.; data curation, A.L.; writing-original draft preparation, A.L.; writing-review and editing, A.L.; visualization, K.P.; supervision, D.Z.; project administration, M.Š.; funding acquisition, M.N. and M.S. All authors have read and agreed to the published version of the manuscript.

Funding: This study was supported from own resources.

Institutional Review Board Statement: The study was conducted according to the guidelines of the Declaration of Helsinki, and approved by the Ethics Committee of University of Rzeszow, Poland (protocol code 12 April 2017, date of approval 21 December 2017) and the Ethics Committee of Wroclaw Medical University, Poland (protocol code 386/2009, date of approval 16 October 2009).

Informed Consent Statement: Informed consent was obtained from all subjects involved in the study.

Data Availability Statement: Data are available on request due to restrictions of privacy and ethics.

Acknowledgments: We would like to thank to all the participants in this study. The authors also thank the regional authorities and hospital managements for permission, cooperation, contributions and logistic support during data collection.

Conflicts of Interest: The authors declare no conflict of interest.

\section{References}

1. Cancer Statistics Center. Available online: https:/ / cancerstatisticscenter.cancer.org (accessed on 22 December 2020).

2. Schüz, J.; Roman, E. Childhood cancer: A global perspective. Cancer Epidemiol. 2021, 71, 101878. [CrossRef] [PubMed]

3. International Agency for Research on Cancer, World Cancer Report. 2020. Available online: https://www.iarc.fr (accessed on 21 December 2020).

4. World Health Organization. Cancer. Available online: https://www.who.int/en/news-room/fact-sheets/detail/cancer (accessed on 27 January 2021).

5. Hughes, N.; Williams, J.; Shaw, C. Supporting the psychological needs of teenagers and young adults during cancer treatment: A literature review. Br. J. Nurs. 2017, 26, S4-S10. [CrossRef]

6. American Cancer Society. Available online: https://www.cancer.org (accessed on 8 November 2020).

7. Steliarova-Foucher, E.; Colombet, M.; Ries, L.A.G.; Moreno, F.; Dolya, A.; Bray, F.; Hesseling, P.; Shin, H.Y.; Stiller, C.A. International incidence of childhood cancer, 2001-2010: A population-based registry study. Lancet Oncol. 2017, 18, 719-731. [CrossRef]

8. Gupta, S.; Howard, S.C.; Hunger, S.P.; Antillon, F.G.; Metzger, M.L.; Israels, T.; Harif, M.; Rodriguez-Galindo, C. Treating Childhood Cancer in Low- and Middle-Income Countries. In Cancer: Disease Control Priorities, 3rd ed.; The International Bank for Reconstruction and Development/The World Bank: Washington, DC, USA, 2015; Volume 3, Chapter 7. [CrossRef]

9. Lam, C.G.; Howard, S.C.; Bouffet, E.; Pritchard-Jones, K. Science and health for all children with cancer. Science 2019, 363, 1182-1186. [CrossRef]

10. Hu, Y.; Wu, L.H.; Guan, H.J.; Wu, S.Y.; Liu, L.Z.; Cai, R.Q.; Xu, Y.J.; Zang, Y.Z.; Sun, X.F.; Zhu, J. Quality of life and related demographic factors in long-term survivors of childhood non-Hodgkin's lymphoma. Zhongguo Dang Dai Er Ke Za Zhi 2021, 23, 882-888. [CrossRef]

11. Zhang, J.; Walsh, M.F.; Wu, G.; Edmonson, M.N.; Gruber, T.A.; Easton, J.; Hedges, D.; Aman, P.; Zhou, X.; Yergeau, D.A.; et al. Germline Mutations in Predisposition Genes in Pediatric Cancer. N. Engl. J. Med. 2015, 373, 2336-2346. [CrossRef] [PubMed]

12. Ehrhardt, M.J.; Hochberg, J.; Bjornard, K.L.; Brinkman, T.M. Long-term survivors of childhood, adolescent and young adult non-Hodgkin lymphoma. Br. J. Haematol. 2019, 185, 1099-1110. [CrossRef] [PubMed]

13. Cheng, L.; Liu, F.; Feng, S.; Wang, Y.; Gu, Y.; Kang, Q. Symptom Experience of Children with Cancer Younger Than Eight Years of Age: An Integrative Review. J. Pain Symptom Manag. 2019, 58, 157-166. [CrossRef]

14. Luna-Fineman, S.; Ortiz, R.; Ilbawi, A. Childhood cancer control during the COVID-19 pandemic. Lancet Oncol. 2021, 22, 1348-1350. [CrossRef]

15. Pope, N.; Tallon, M.; McConigley, R.; Wilson, S. The experiences of acute non-surgical pain of children who present to a healthcare facility for treatment: A systematic review protocol. JBI Database Syst. Rev. Implement. Rep. 2015, 13, 12-20. [CrossRef] [PubMed]

16. Kazak, A.E.; Barakat, L.P.; Meeske, K.; Christakis, D.; Meadows, A.T.; Casey, R.; Penati, B.; Stuber, M.L. Posttraumatic stress, family functioning, and social support in survivors of childhood leukemia and their mothers and fathers. J. Consult. Clin. Psychol. 1997, 65, 120-129. [CrossRef]

17. Eapen, V.; Mpofu, C.; Revesz, T.; Daradkeh, T. Self-Perception Profile in Children with Cancer: Self vs. Parent Report. Psychol. Rep. 1999, 84, 427-432. [CrossRef] [PubMed]

18. McCaffrey, C.N. Major Stressors and Their Effects on the Well-Being of Children with Cancer. J. Pediatr. Nurs. 2006, 21, 59-66. [CrossRef] 
19. Zhukovsky, D.; Rozmus, C.; Robert, R.; Bruera, E.; Wells, R.; Cohen, M. Symptom and Illness Experience for English and Spanish-Speaking Children with Advanced Cancer: Child and Parent Perspective. Children 2021, 8, 657. [CrossRef]

20. Reisi-Dehkordi, N.; Baratian, H.; Zargham-Boroujeni, A. Challenges of children with cancer and their mothers: A qualitative research. Iran J. Nurs. Midwifery Res. 2014, 19, 334-339.

21. Kohi, T.W.; Von Essen, L.; Masika, G.M.; Gottvall, M.; Dol, J. Cancer-related concerns and needs among young adults and children on cancer treatment in Tanzania: A qualitative study. BMC Cancer 2019, 19, 82. [CrossRef]

22. Chien, C.-H.; Chang, Y.-Y.; Huang, X.-Y. The Lived Experiences of Adolescents with Cancer: A Phenomenological Study. Clin. Nurs. Res. 2018, 29, 217-225. [CrossRef]

23. Epstein, I.; Orr, P.; Stevens, B. The experience of suffering in children with cancer-A meta-synthesis. Suff. Child Multidiscip. J. Child Pain. 2004, 5, 1-8.

24. Dyson, G.J.; Thompson, K.; Palmer, S.; Thomas, D.M.; Schofield, P. The relationship between unmet needs and distress amongst young people with cancer. Support. Care Cancer 2011, 20, 75-85. [CrossRef]

25. Hedström, M.; Ljungman, G.; Von Essen, L. Perceptions of Distress among Adolescents Recently Diagnosed with Cancer. J. Pediatr. Hematol. Oncol. 2005, 27, 15-22. [CrossRef]

26. Dudek, M. Depression among high-schoolstudents. Rocz. Kom. Nauk. Pedagog. 2014, 67I, 139-151.

27. Verberne, L.M.; Maurice-Stam, H.; Grootenhuis, M.A.; Van Santen, H.M.; Schouten-Van Meeteren, A.Y. Sleep disorders in children after treatment for a CNS tumour. J. Sleep Res. 2012, 21, 461-469. [CrossRef]

28. Lee, M.-Y.; Mu, P.-F.; Tsay, S.-F.; Rn, S.C.; Chen, Y.-C.; Wong, T. Body image of children and adolescents with cancer: A metasynthesis on qualitative research findings. Nurs. Health Sci. 2012, 14, 381-390. [CrossRef]

29. Kamper, R.; Van Cleve, L.; Savedra, M. Children with Advanced Cancer: Responses to a Spiritual Quality of Life Interview. J. Spéc. Pediatr. Nurs. 2010, 15, 301-306. [CrossRef]

30. Wiffen, P.J.; E Cooper, T.; Anderson, A.-K.; Gray, A.; Grégoire, M.-C.; Ljungman, G.; Zernikow, B. Opioids for cancer-related pain in children and adolescents. Cochrane Database Syst. Rev. 2017, 7, CD012564. [CrossRef]

31. Boland, E.; Ahmedzai, S. Persistent pain in cancer survivors. Curr. Opin. Support. Palliat. Care 2017, 11, 181-190. [CrossRef] [PubMed]

32. Meeske, K.; Katz, E.R.; Palmer, S.N.; Burwinkle, T.; Varni, J.W. Parent proxy-reported health-related quality of life and fatigue in pediatric patients diagnosed with brain tumors and acute lymphoblastic leukemia. Cancer 2004, 101, 2116-2125. [CrossRef]

33. Razzouk, B.I.; Hord, J.D.; Hockenberry, M.; Hinds, P.S.; Feusner, J.; Williams, D.; Rackoff, W.R. Double-Blind, Placebo-Controlled Study of Quality of Life, Hematologic End Points, and Safety of Weekly Epoetin Alfa in Children with Cancer Receiving Myelosuppressive Chemotherapy. J. Clin. Oncol. 2006, 24, 3583-3589. [CrossRef]

34. Lau, J.T.F.; Yu, X.-N.; Chu, Y.; Shing, M.M.K.; Wong, E.M.C.; Leung, T.F.; Li, C.K.; Fok, T.F.; Mak, W.W.S. Validation of the Chinese version of the Pediatric Quality of Life InventoryTM (PedsQLTM) Cancer Module. J. Pediatr. Psychol. 2009, 35, 99-109. [CrossRef]

35. Tsuji, N.; Kakee, N.; Ishida, Y.; Asami, K.; Tabuchi, K.; Nakadate, H.; Iwai, T.; Maeda, M.; Okamura, J.; Kazama, T.; et al. Validation of the Japanese version of the Pediatric Quality of Life Inventory (PedsQL) Cancer Module. Health Qual. Life Outcomes 2011, 9, 22. [CrossRef]

36. Kestler, G.L.-W.S.A.; LoBiondo-Wood, G. Review of Symptom Experiences in Children and Adolescents with Cancer. Cancer Nurs. 2012, 35, E31-E49. [CrossRef]

37. Van Cleve, L.; Bossert, E.; Beecroft, P.; Adlard, K.; Alvarez, O.; Savedra, M.C. The Pain Experience of Children with Leukemia During the First Year After Diagnosis. Nurs. Res. 2004, 53, 1-10. [CrossRef] [PubMed]

38. Zupanec, S.; Jones, H.; Stremler, R. Sleep Habits and Fatigue of Children Receiving Maintenance Chemotherapy for ALL and Their Parents. J. Pediatr. Oncol. Nurs. 2010, 27, 217-228. [CrossRef] [PubMed]

39. Tomlinson, D.; Tigelaar, L.; Hyslop, S.; Lazor, T.; Dupuis, L.L.; Griener, K.; Oliveria, J.; Sung, L. Self-report of symptoms in children with cancer younger than 8 years of age: A systematic review. Support. Care Cancer 2017, 25, 2663-2670. [CrossRef] [PubMed]

40. Pinheiro, L.C.; McFatrich, M.; Lucas, N.; Walker, J.S.; Withycombe, J.S.; Hinds, P.S.; Sung, L.; Tomlinson, D.; Freyer, D.R.; Mack, J.W.; et al. Child and adolescent self-report symptom measurement in pediatric oncology research: A systematic literature review. Qual. Life Res. 2018, 27, 291-319. [CrossRef]

41. Tomlinson, D.; Zupanec, S.; Jones, H.; O'Sullivan, C.; Hesser, T.; Sung, L. The lived experience of fatigue in children and adolescents with cancer: A systematic review. Support. Care Cancer 2016, 24, 3623-3631. [CrossRef]

42. Perdikaris, P.; Merkouris, A.; Patiraki, E.; Papadatou, D.; Vasilatou-Kosmidis, H.; Matziou, V. Changes in children's fatigue during the course of treatment for paediatric cancer. Int. Nurs. Rev. 2008, 55, 412-419. [CrossRef] [PubMed]

43. Pöder, U.; Ljungman, G.; von Essen, L. Parents' Perceptions of Their Children's Cancer-Related Symptoms During Treatment: A Prospective, Longitudinal Study. J. Pain Symptom Manag. 2010, 40, 661-670. [CrossRef]

44. Enskär, K.; von Essen, L. Prevalence of aspects of distress, coping, support and care among adolescents and young adults undergoing and being off cancer treatment. Eur. J. Oncol. Nurs. 2007, 11, 400-408. [CrossRef]

45. Hedström, M.; Kreuger, A.; Ljungman, G.; Nygren, P.; von Essen, L. Accuracy of assessment of distress, anxiety, and depression by physicians and nurses in adolescents recently diagnosed with cancer. Pediatr. Blood Cancer 2006, 46, 773-779. [CrossRef]

46. Sanford, S.D.; Okuma, J.O.; Pan, J.; Srivastava, D.K.; West, N.; Farr, L.; Hinds, P.S. Gender Differences in Sleep, Fatigue, and Daytime Activity in a Pediatric Oncology Sample Receiving Dexamethasone. J. Pediatr. Psychol. 2007, 33, 298-306. [CrossRef] 
47. Edwards, L.B.; Greeff, L.E. A descriptive qualitative study of childhood cancer challenges in South Africa: Thematic analysis of 68 photovoice contributions. S. Afr. J. Oncol. 2017, 1, 8. [CrossRef]

48. Lee, Y.-L.; Santacroce, S.J. Posttraumatic stress in long-term young adult survivors of childhood cancer: A questionnaire survey. Int. J. Nurs. Stud. 2007, 44, 1406-1417. [CrossRef]

49. Tseng, T.-H.; Cleeland, C.S.; Wang, X.S.; Lin, C.-C. Assessing Cancer Symptoms in Adolescents with Cancer Using the Taiwanese Version of the M. D. Anderson Symptom Inventory. Cancer Nurs. 2008, 31, E9-E16. [CrossRef]

50. Davison, T.E.; McCabe, M. Adolescent Body Image and Psychosocial Functioning. J. Soc. Psychol. 2006, 146, 15-30. [CrossRef]

51. Pendley, J.S.; Dahlquist, L.M.; Dreyer, Z. Body Image and Psychosocial Adjustment in Adolescent Cancer Survivors. J. Pediatr. Psychol. 1997, 22, 29-43. [CrossRef]

52. Bellizzi, K.M.; Smith, A.; Schmidt, S.; Keegan, T.H.M.; Zebrack, B.; Lynch, C.F.; Deapen, D.; Shnorhavorian, M.; Tompkins, B.J.; Simon, M.; et al. Positive and negative psychosocial impact of being diagnosed with cancer as an adolescent or young adult. Cancer 2012, 118, 5155-5162. [CrossRef]

53. Vance, Y.H.; Eiser, C. The school experience of the child with cancer. Child Care Health Dev. 2002, 28, 5-19. [CrossRef]

54. Quinn, G.P.; Gonçalves, V.; Sehovic, I.; Bowman, M.L.; Reed, D.R. Quality of life in adolescent and young adult cancer patients: A systematic review of the literature. Patient Relat. Outcome Meas. 2015, 6, 19-51. [CrossRef]

55. Bonevski, B.; Sanson-Fisher, R.; Girgis, A.; Burton, L.; Cook, P.; Boyes, A.; the Supportive Care Review Group. Evaluation of an instrument to assess the needs of patients with cancer. Cancer 2000, 88, 217-225. [CrossRef] 